\title{
Percutaneous cement augmentation in the treatment of osteoporotic vertebral fractures (OVFs) in the elderly: a systematic review
}

\author{
I. Sanli ${ }^{1}$ - S. M. J. van Kuijk ${ }^{2}$ R. A. de Bie ${ }^{2}$ - L. W. van Rhijn ${ }^{1}$ P. C. Willems ${ }^{1}$
}

Received: 16 February 2020 / Revised: 16 February 2020 / Accepted: 21 March 2020 / Published online: 2 April 2020

(c) The Author(s) 2020

\begin{abstract}
Purpose A systematic review, to study treatment effects for osteoporotic vertebral fractures (OVFs) in the elderly including all available evidence from controlled trials on percutaneous cement augmentation.

Methods Primary studies, published up to December, 2019, were searched in PubMed and the Cochrane Library. Selected were all prospective controlled studies including patients $>65$ years of age and reporting on at least one main outcome. Main outcomes were pain, disability and quality of life (QOL) 1 day post-intervention and at 6 months postoperatively. Excluded were meta-analyses or reviews, retrospective or non-controlled studies, case studies, patients' groups with neoplastic and/ or traumatic fractures and/or neurologically compromised patients.

Results Eighteen studies comprising 2165 patients ( $n=1117$ percutaneous cement augmentation, $n=800$ conservative treatment (CT), $n=248$ placebo) with a mean follow-up of up to 12 months were included. Pooled results showed significant pain relief in favor of percutaneous cement augmentation compared to CT, direct postoperative and at 6 months follow-up. At 6 months, a significant difference was observed for functional disability scores in favor of percutaneous cement augmentation. When comparing percutaneous cement augmentation to placebo, no significant differences were observed.

Conclusion This review incorporates all current available evidence (RCTs and non-RCTs) on the efficacy of percutaneous cement augmentation in the treatment of OVFs in the elderly. Despite methodological heterogeneity of the included studies, this review shows overall significant sustained pain relief and superior functional effect in the short- and long term for percutaneous cement augmentation compared to conservative treatment.
\end{abstract}

\section{Graphic abstract}

These slides can be retrieved under Electronic Supplementary Material.
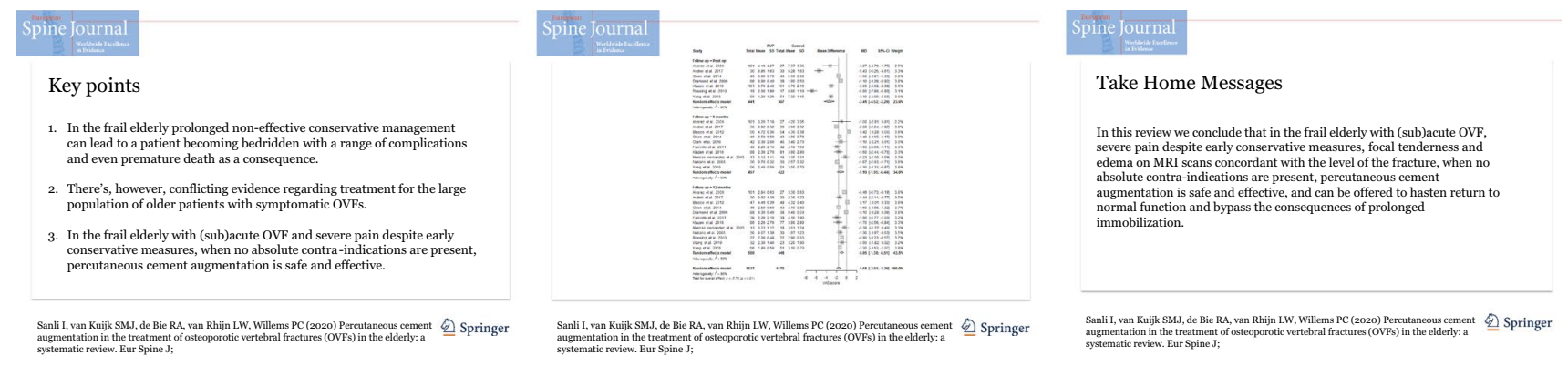

Keywords Elderly $\cdot$ Percutaneous cement augmentation $\cdot$ Osteoporotic vertebral fracture $\cdot$ Conservative treatment $\cdot$ Sham treatment

Electronic supplementary material The online version of this article (https://doi.org/10.1007/s00586-020-06391-x) contains supplementary material, which is available to authorized users.

Extended author information available on the last page of the article 


\section{Introduction}

Worldwide osteoporosis causes more than 8.9 million fractures annually [1]. The combined lifetime risk for wrist, hip and spine fractures coming to clinical attention is on average $40 \%$ and equals the risk of cardiovascular disease [2]. Three-quarters of these fractures affect patients of 65 years and older [3]. Mortality rates of osteoporotic vertebral fractures (OVFs) are high and exceed those of hip fractures [4].

In the elderly, a high risk of falling is not uncommon. In addition, aging is accompanied by a loss of bone stock leading to osteoporosis with a higher risk of fractures. In the elderly population, osteoporosis is one of the most important factors that affect quality of life. Management of OVFs focuses on pain relief and independence in activities of daily living.

When despite conservative treatment OVF patients suffer from immobility caused by pain, dependency and/or additional complications due to being bedridden, surgical interventions should be considered. However, due to the osteoporosis and other comorbidities in the elderly patient, major invasive surgery should be avoided. It remains unclear whether an effective and safe minimally invasive surgical treatment is available for elderly patients with symptomatic OVFs. A recent meta-analysis of RCTs concluded that percutaneous vertebroplasty (PV) and percutaneous kyphoplasty (PKP) significantly decrease pain when compared to conservative treatment [5]. However, not in all countries PV/PKP acknowledged effective treatments for OVFs and recommended as such in national guidelines. A recent Cochrane review concluded that there is a lack of high-quality evidence to support the benefit of any minimal invasive surgical technique and noticed a potential for harm in the treatment of OVF [6].

This manuscript aims to provide an updated comprehensive review on the use of percutaneous cement augmentation, with a special focus on the frail elderly with symptomatic OVFs, using data from RCTs and prospective non-RCTs comparing PV or PKP with conservative treatment or sham procedures.

\section{Materials and methods}

This systematic review and meta-analysis are reported according to the Preferred Reporting Items for Systematic Reviews and Meta-analyses (PRISMA) statement.

\section{Search strategy and selection criteria}

PubMed and Cochrane databases were searched up to December 1, 2019, for primary research articles, focusing on minimally invasive surgical procedures for the treatment of OVF in elderly patients.

Search terms were: $(((()($ medical treatment $)$ OR optimal medical treatment) OR conservative treatment) OR non-surgical treatment) OR placebo) AND full text AND Humans[MESH] AND aged[MESH])) AND (aged [MESH] OR elderly)) AND (comparative effectiveness research [MESH]) OR patient safety [MESH]) OR pain Measurement [MESH]) OR effectivity) OR effectiveness) OR success rate) OR success) OR safety) OR patient safety) OR pain relief assessment) OR visual analog scale $))))$ AND $((((((()(((($ kyphoplasty [MESH] $))$ OR vertebroplasty [MESH]) OR kyphoplasty) OR balloon kyphoplasty) OR vertebroplasty) OR percutaneous screw fixation) OR less invasive treatment) OR minimal invasive treatment) OR minimal invasive surgical procedure) OR minimal invasive surgery) OR less invasive surgical procedure) OR less invasive surgery $))))$ AND (((()(((((osteoporotic compression fracture) OR osteoporotic vertebral fracture) OR spinal fractures [MESH]) OR osteoporosis) OR osteoporosis [MESH]))).

We selected all controlled studies in which patients in the age group $>65$ years were treated. Abstracts were reviewed by two reviewers (P.W and I.S). For studies meeting the eligibility criteria, full-text articles were obtained. Two authors independently reviewed the text of each study and came to a mutual decision on which studies to include. We examined reference lists of included studies for any additional relevant studies. For studies with the same study protocol and/or study sample, only the most recent or most comprehensive paper with longest follow-up data was included. In case of disagreement, a third reviewer (R.d.B) was consulted for consensus. When necessary, authors were contacted for provision of additional data.

Studies were excluded that did not report outcomes that met the inclusion criteria, being meta-analyses, retrospective analyses, review articles, non-controlled studies, studies which included neoplastic and/or traumatic fractures and/or neurologic compromises patients, as well as case reports.

Two reviewers (P.W and I.S) independently evaluated the risk of bias of included studies using the risk of bias assessment from the Cochrane Handbook, version 5.1.0 [7]. Bias risk assessment included seven aspects: random sequence generation (selection bias), allocation concealment (selection bias), blinding of participants and personnel (performance bias), blinding of outcome assessment (detection bias), incomplete outcome data (attrition bias), 
selective reporting (reporting bias) and other potential sources of bias. Three levels were used to evaluate the trials: low risk of bias (all the items were in low risk of bias), high risk of bias (at least one item was in high risk of bias) and unclear risk of bias (at least one item was in unclear risk of bias).

\section{Data analysis}

The main outcome measures were: pain relief (assessed on a $0-100 \mathrm{~mm}$ VAS or $0-10$ point NRS) at 1 day postoperatively and at 6 months, functional disability (RMDQ and ODI) and QOL (QUALEFFO-41) at 6 months [8-10]. The secondary outcome measure was: safety (expressed as morbidity and/ or mortality). Data of intention-to-treat analyses were used, if applicable, wherein data from all patients were analyzed on the basis of their initial group allocations.

Mean differences (MDs) and 95\% confidence intervals (CI) were calculated, and used as measure of effect. For continuous outcomes with no SDs, we calculated SD from 95\% CIs. If no measures of variance were reported, we used the pooled SD of other trials included in the same analysis. Testing for between-study homogeneity was done using $I^{2}$. An $I^{2}>50 \%$ was considered to indicate significant heterogeneity, and in those cases, we used the random effects model to pool results. In all other cases, we used a fixed effects model. Results are presented as forest plots. Analyses were performed using $\mathrm{R}$ version 3.5.1 and the meta-package. A two-sided $p<0.05$ was considered statistically significant.

\section{Results}

The primary search identified 1250 references. After filtering for full-text human studies, 968 records remained and were screened. References of retrieved papers were searched manually. Eighteen studies were eligible for inclusion (11 RCTs and seven prospective non-RCTs comparing percutaneous cement augmentation with conservative treatment or placebo). A PRISMA flow diagram of the study selection process is shown in Fig. 1.

All included studies were either prospective RCTs or nonRCTs (see Table 1) [11-28]. Baseline characteristics of all included study population are shown in Table 2.

Risk of bias of individual studies was assessed. Eight RCTs were considered as having low risk of selection bias, seven RCTs showed low risk attrition bias and five RCTs low risk reporting bias. The placebo/sham-controlled studies were overall of better methodological quality with lower risk of bias comparing to the other included RCTs (see Table 3).

The pooled results of the included studies indicate that percutaneous cement augmentation is a safe procedure (see Table 4 and Fig. 2).

\section{Pain}

The included $12 \mathrm{PVs}$ versus conservative treatment studies were heterogeneous $\left(p<0.00001, I^{2}=93 \%\right)$. Pooled results indicated no significant differences in pain at baseline between the PV and conservative treatment group, the PKP versus conservative treatment group and PV versus placebo.

Seven PVs versus conservative treatment studies reported direct postoperative outcomes at day one. The pooled results showed heterogeneity and significant pain relief in favor of PV. MDs were, respectively, $-1.73(-1.87,-1.60)$; $p<0.00001, I^{2}=98 \%$. None of the two studies reported direct postoperative outcomes for PKP versus conservative treatment. One RCT comparing PV versus placebo presented direct postoperative results at day one, with no significant difference (see Fig. 3).

Ten PVs versus conservative treatment studies, and two studies comparing PKP with conservative treatment, reported 6 months outcomes. Although clinically comparable, the studies were statistically heterogeneous, and therefore not pooled. All showed significant pain relief in favor of PV. MDs were $-1.08(-1.16,-1.00)$ for PV versus conservative treatment. MDs were $-0.39(-0.57,-0.20)$ for PKP (two studies) versus conservative treatment. The PV versus placebo groups (four studies) showed no significant pain relief in favor of one of the two groups. The MD was $-0.58(-1.09,-0.08) ; p=0.63, I^{2}=0 \%$ (see Fig. 4). Results were sustained at 12-month follow-up (see Figs. 5, 6).

\section{Functional outcomes}

At 6-month follow-up, there was significant difference in RMDQ scores in favor of the PV group compared to conservative treatment (two studies) with a total MD of -1.77 (CI $-2.13,-1.42) ; p<0.0001$ and for PKP versus conservative treatment (one study) with a total MD of -2.89 (CI $-4.32,-1.46) ; p<0.00001$.

For ODI scores at 6-month follow-up, the pooled results were in favor of PV versus conservative treatment (four studies) with a total MD of -12.30 (CI $-16.46,-8.13)$; $p<0.00001, I^{2}=96 \%$.

In the PV versus placebo groups, no significant difference in functional outcome results was found (see Fig. 7).

\section{Qol}

QOL (QUALEFFO-41) was recorded in three of the 12 included PVs versus conservative treatment studies, and two of the PVs versus placebo studies. There was no significant difference in scores at 6-month follow-up (see Fig. 8). 
Fig. 1 PRISMA flowchart

Unique records

identified through

database

searching (up to 1

December 2019):

$n=1250$

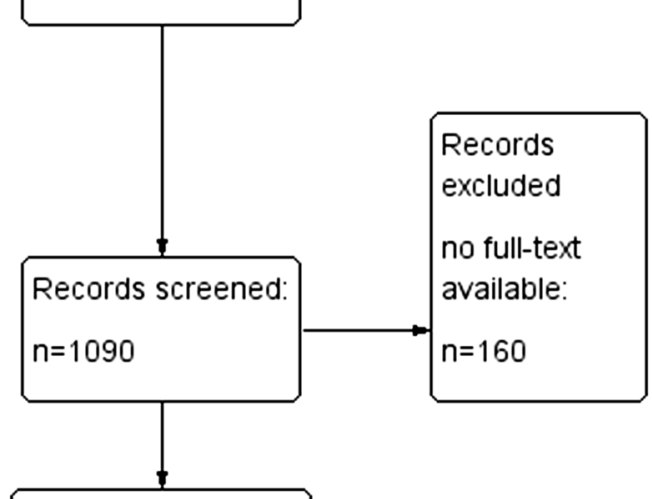

Full-text human

studies assessed

for eligibility:

$n=968$
Additional

records

identified

through

referencelists,

included by

selectioncriteria

$n=3$

Full-text articles excluded: $n=686$,

with reasons:

not reporting outcomes that meet

inclusion criteria: $n=448$

case-reports: $n=11$

meta-analysis/reviews/guidelines:

$n=114$

studies and/or

clinical trials:

$n=282$

duplicate publications: $n=12$

non-english publications: $n=101$

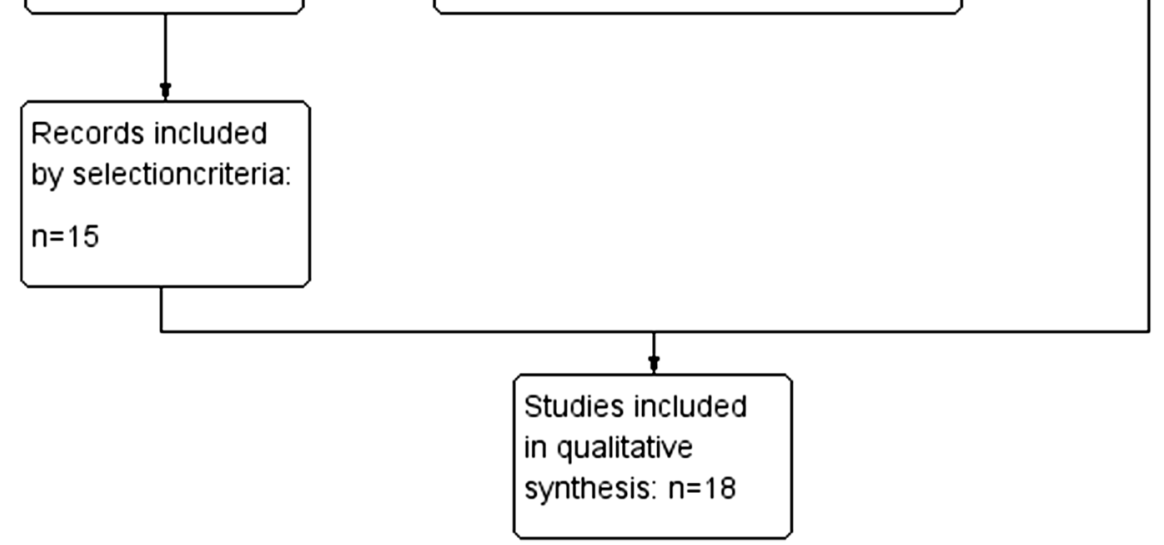




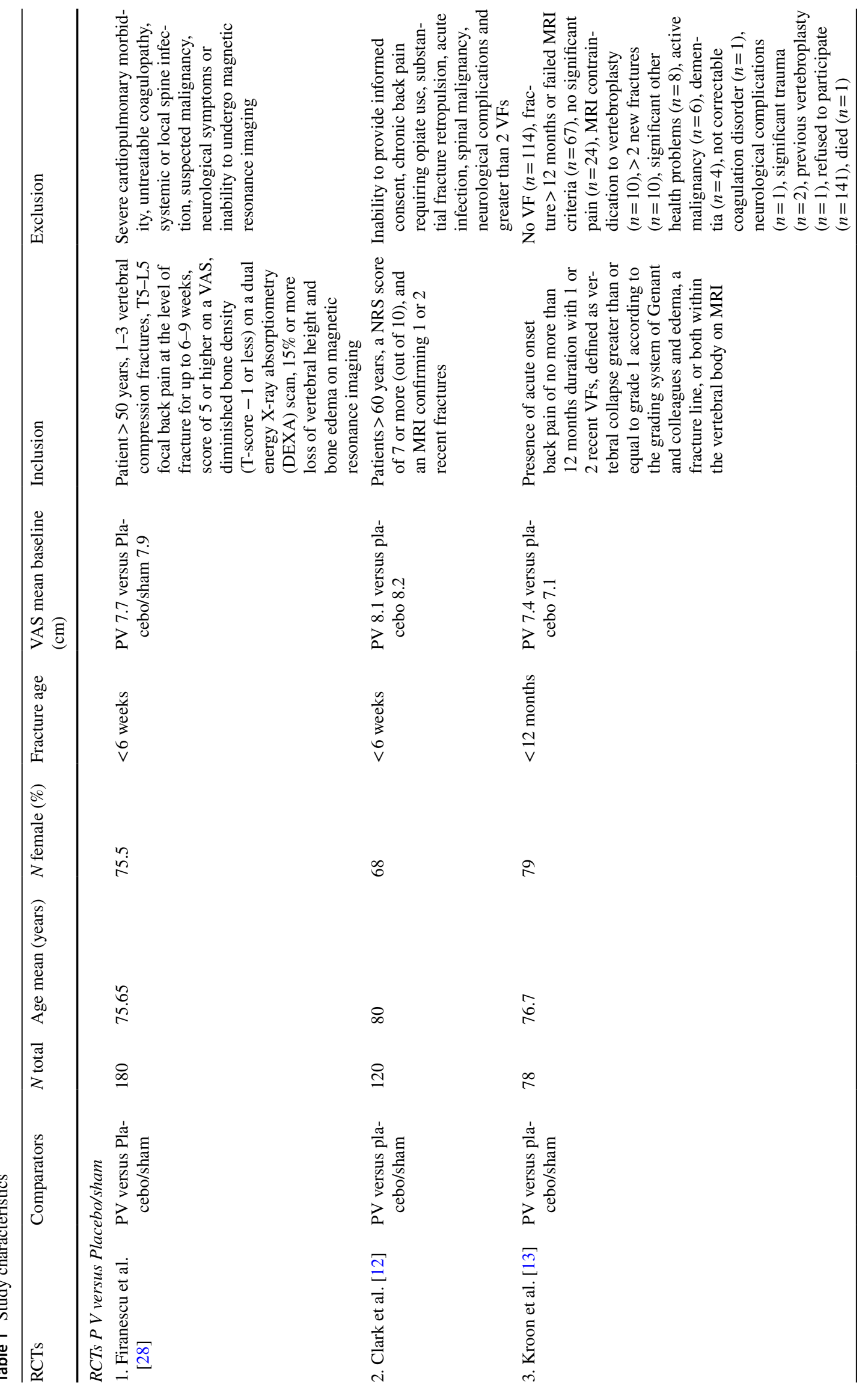




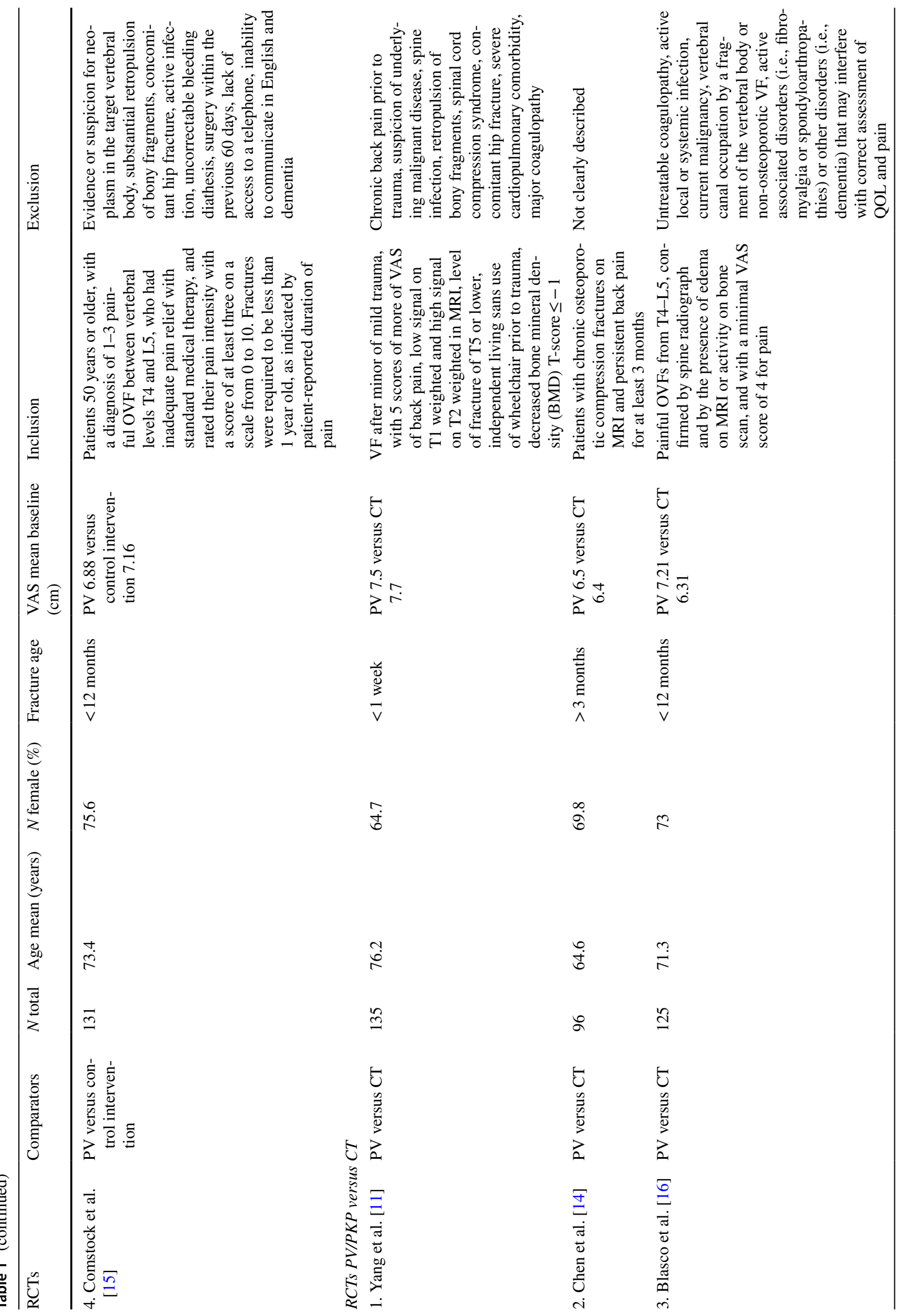




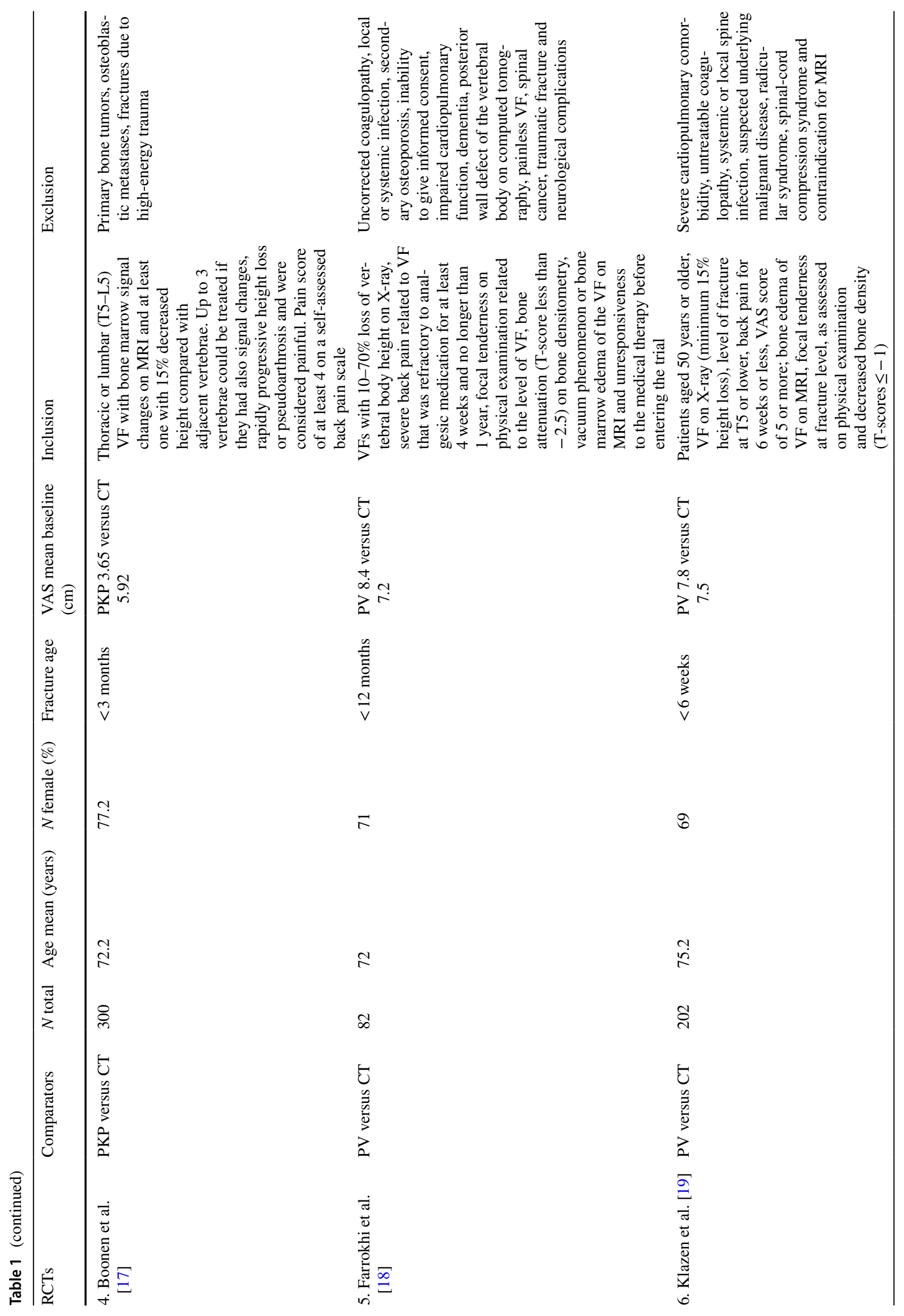




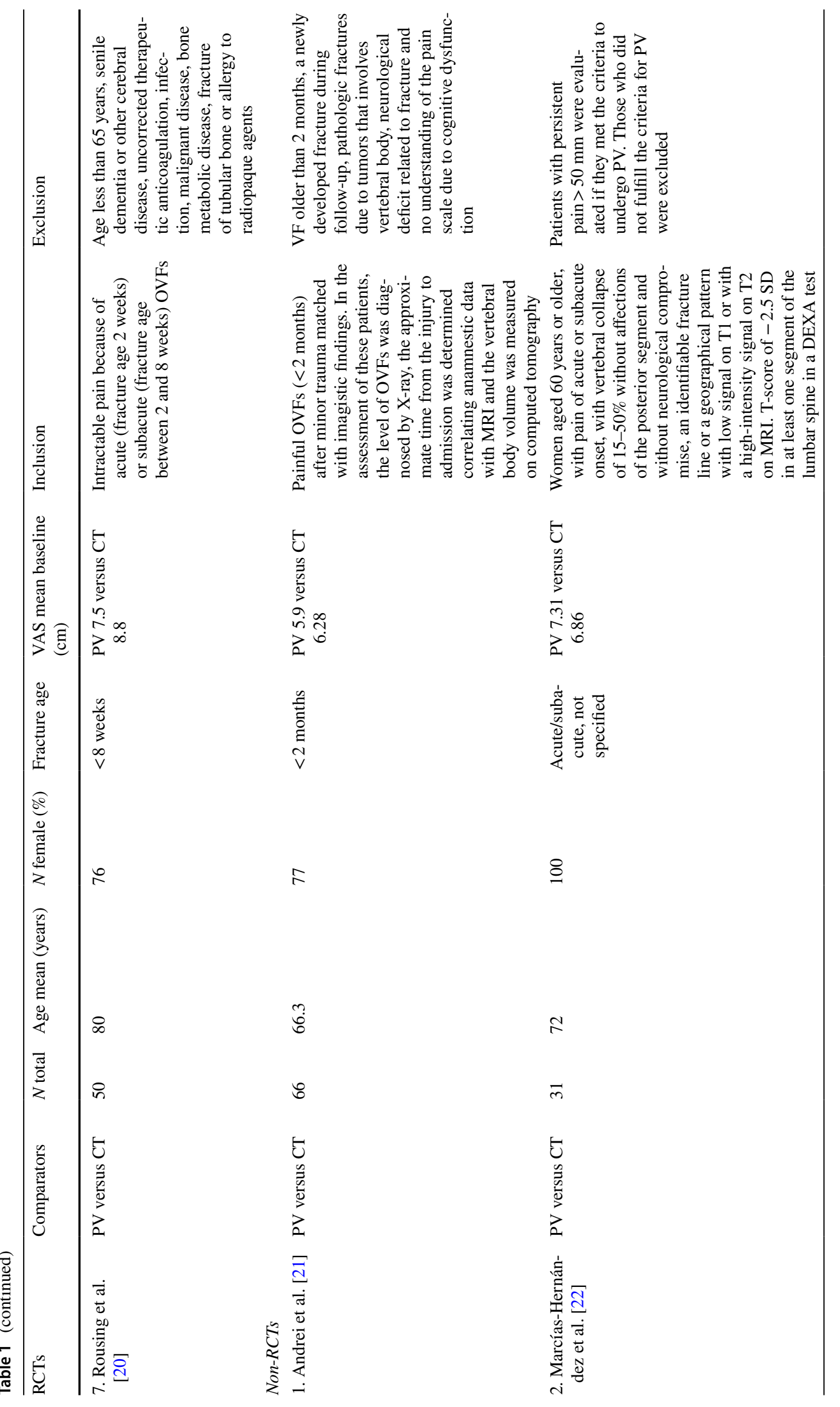




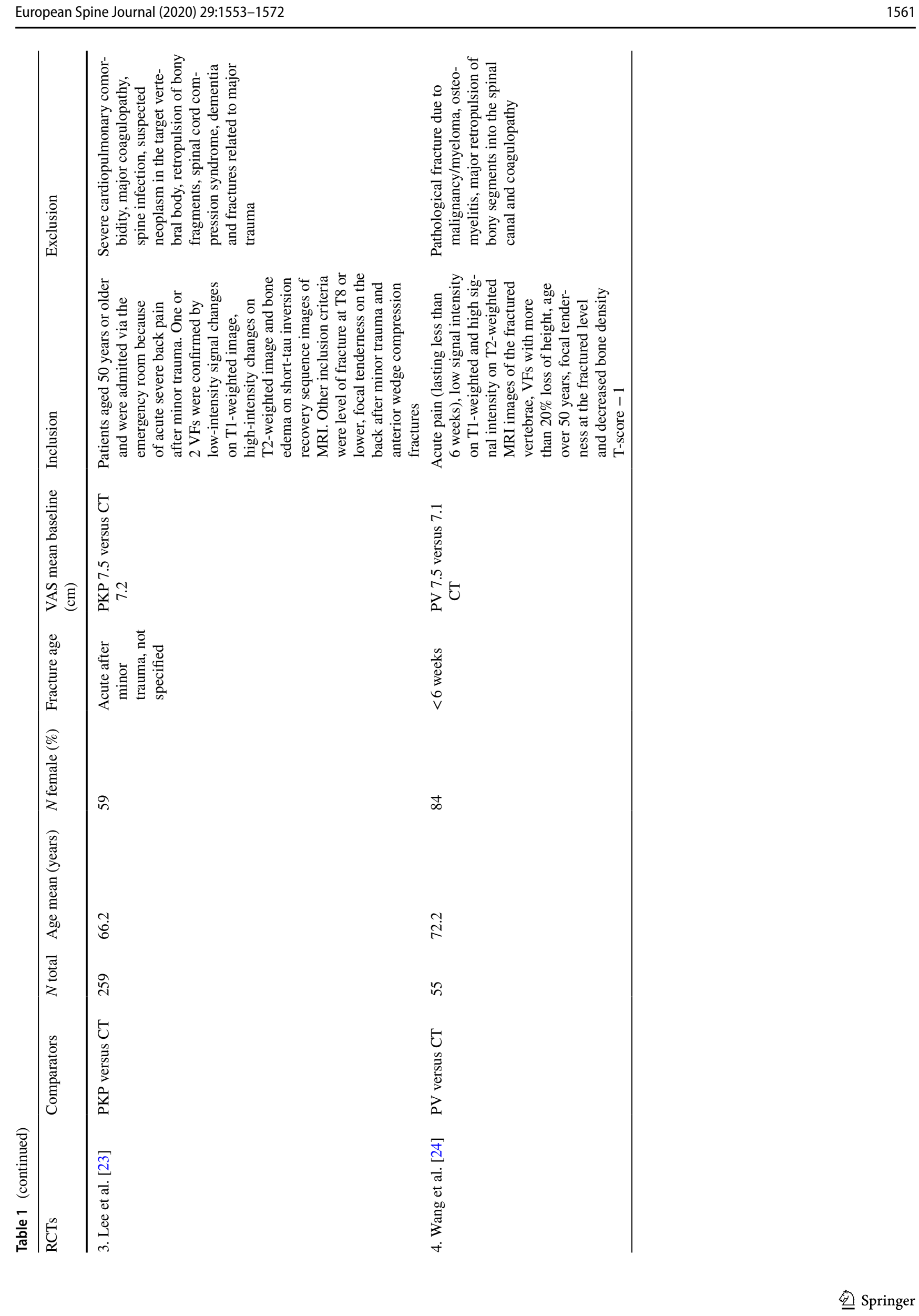




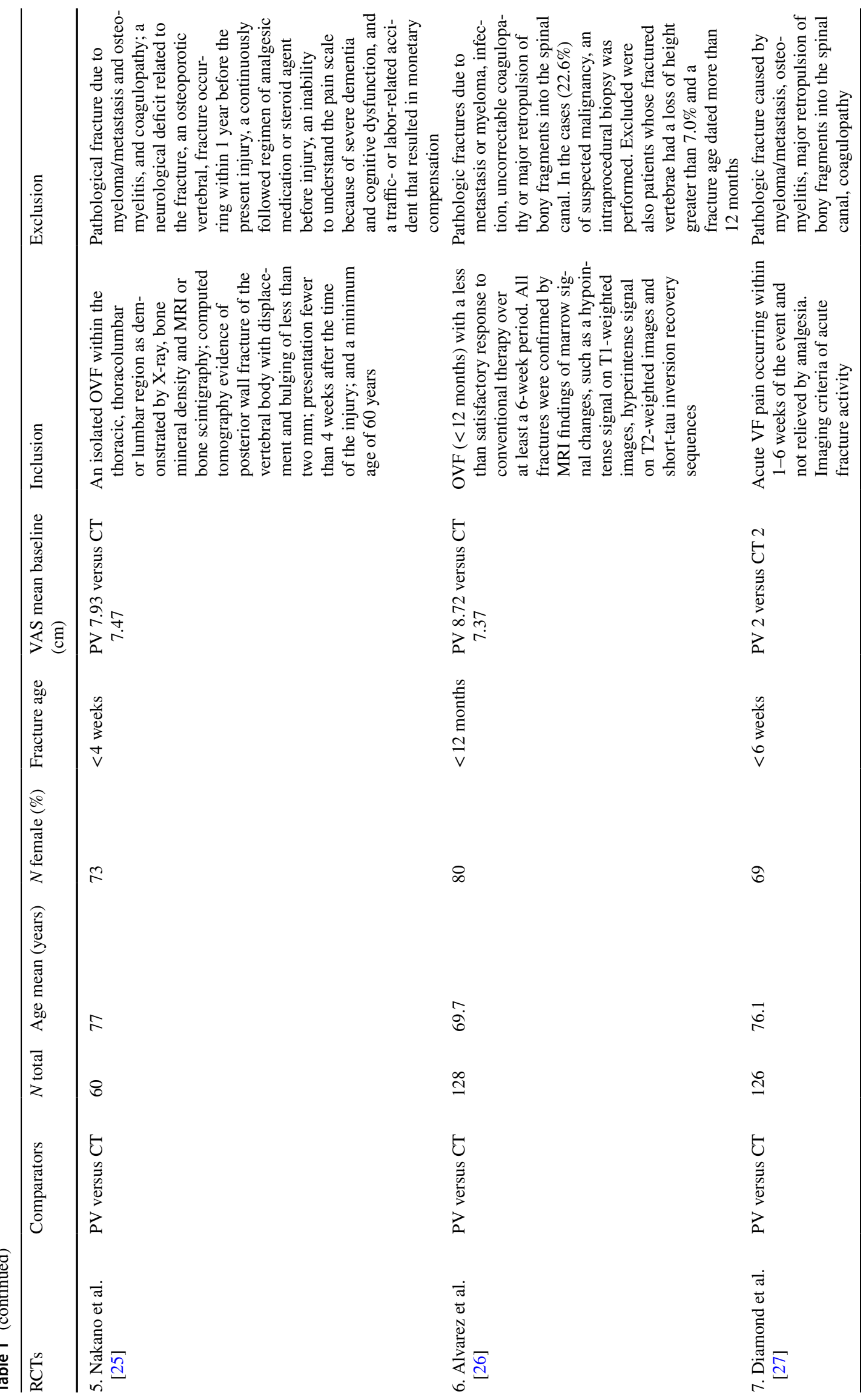


Table 2 Baseline characteristics study population

\begin{tabular}{ll}
\hline Age mean (range years) & 74 (65-80) \\
Female patients (\%) & 60 \\
Fracture-age ( $n=$ studies) & \\
$<6$-9 weeks & 9 \\
$<3$ months & 1 \\
$>3$ months & 1 \\
$<12$ months & 5 \\
Non-specified/acute/subacute fractures & 2 \\
Comparators ( $n=$ studies) & \\
PV versus CT & 12 \\
PV versus sham/placebo & 4 \\
PKP versus CT & 2
\end{tabular}

\section{Discussion}

In this systematic review, we included all retrievable prospective controlled trials that compared percutaneous cement augmentation to conservative treatment or placebo in the management of OVFs in the elderly. Pooled results indicate significant pain relief and functional improvement up to 12 months of follow-up for percutaneous cement augmentation compared to conservative treatment.

Consensus guidelines about the role of percutaneous cement augmentation in OVFs are lacking, and divergent opinions exist. In the European Guidance for the diagnosis and management of osteoporosis in postmenopausal women, a role for percutaneous cement augmentation has been suggested in patients with recent OVF in whom pain persists for 2-3 weeks despite a well-conducted analgesic program [29]. In accordance with the European guidance, the UK NICE guidelines recommend percutaneous cement augmentation only in patients who have severe ongoing pain after a recent, unhealed fracture despite optimal pain management [30]. The American Academy of Orthopaedic Surgeons strongly recommends against vertebroplasty based on evidence regarding two Level I studies that compared vertebroplasty to a sham procedure and showed no significant difference between the two procedures in pain relief and function [31]. However, these two studies have been criticized thoroughly $[32,33]$ : Both studies included patients with symptoms of up to 1-year duration, which is a time period in which fractures can heal naturally. Moreover, patients with an NRS score of three points out of ten were eligible for inclusion. Ryu and Park reported that there is a strong correlation between severity of pre-intervention pain score and the post-intervention outcome; more severe pain resulted in more significant improvement following PV [34]. The low participation rates
Table 3 Risk of bias

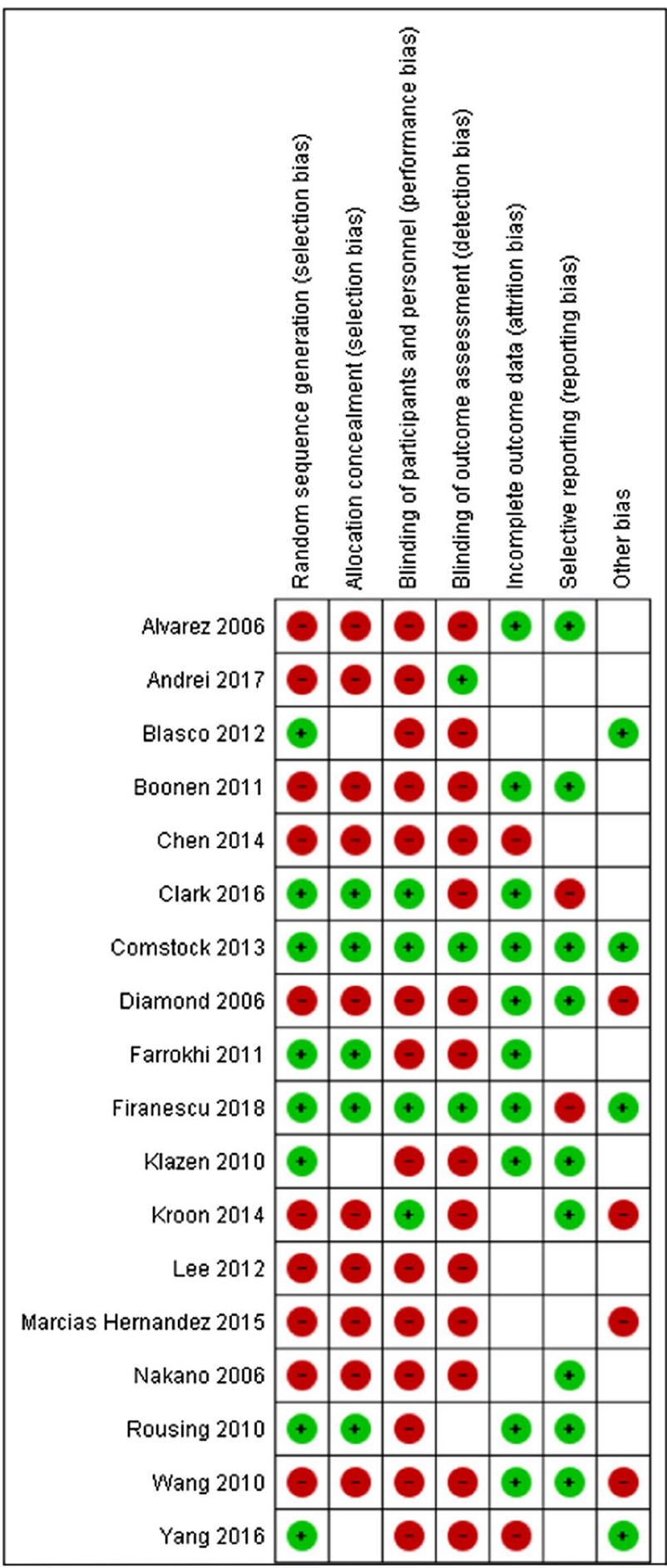

Low risk

High risk

Unclear risk 


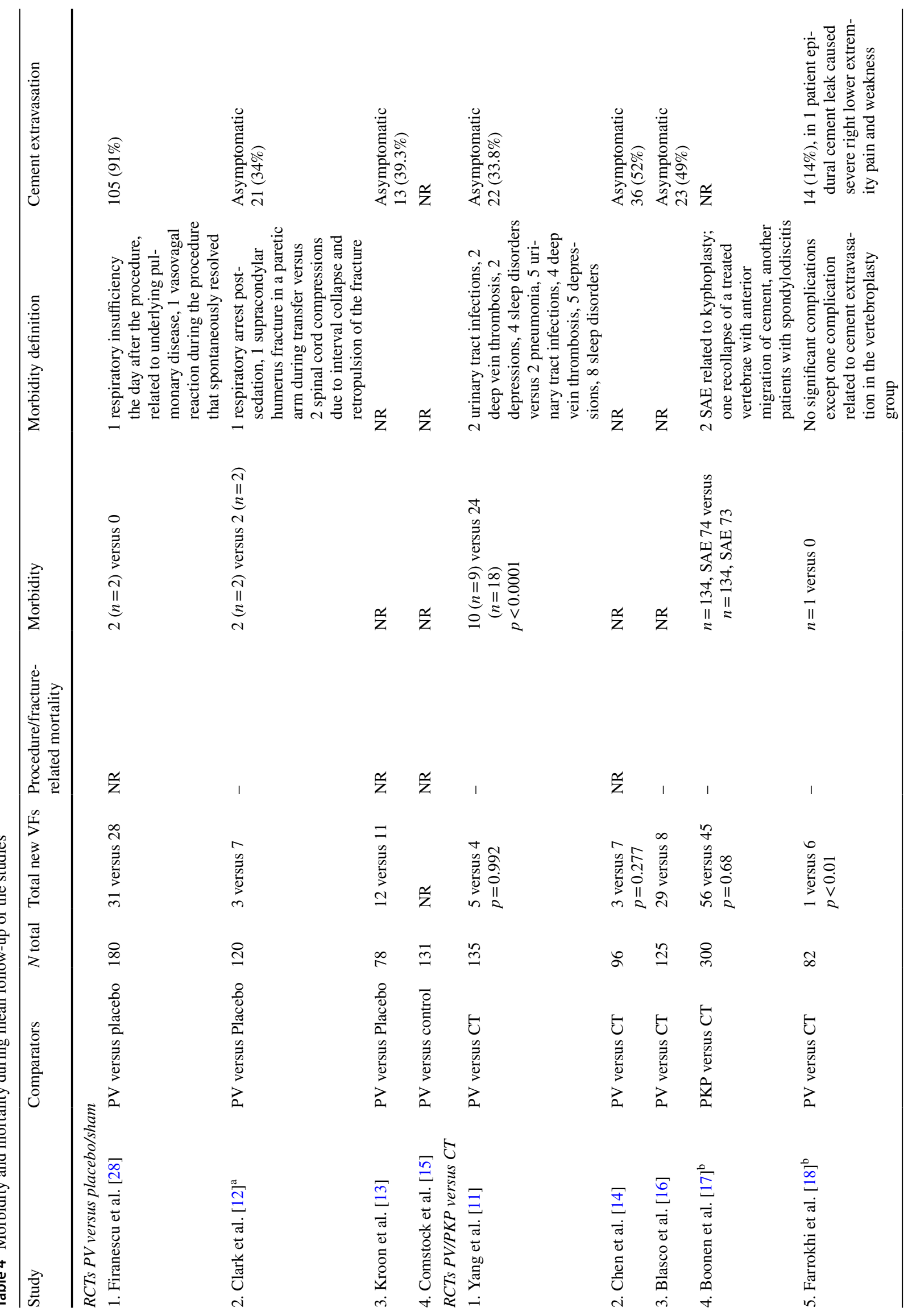




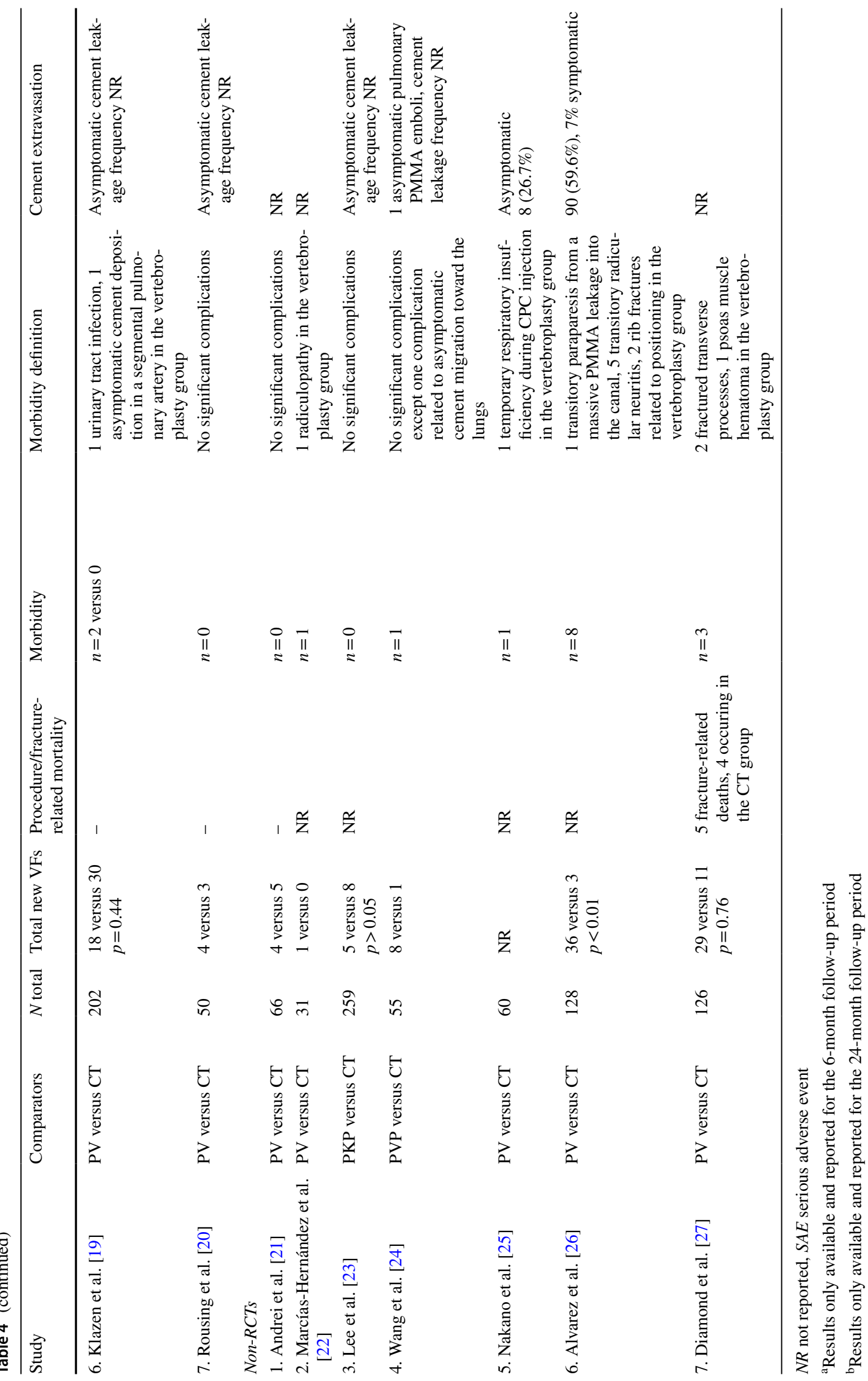


Fig. 2 Random effects model plot of cement extravasation
Study

Events Total

Proportion

95\%-Cl Weight

Firanescu et al. 2018

Clark et al. 2016

Kroon et al. $2014^{\circ}$

Yang et al. 2016

Chen et al. 2014

Blasco et al. 2012

Farrokhi et al. 2011

Nakano et al. 2006

Alvarez et al. 2006

Random effects model

Heterogeneity: $I^{2}=96 \%$

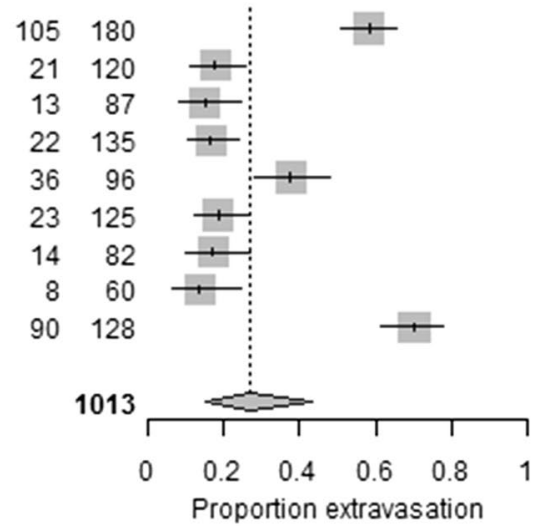

$0.58[0.51 ; 0.66] 11.5 \%$

$0.18[0.11 ; 0.25] 11.2 \%$

$0.15[0.08 ; 0.24] 10.9 \%$

$0.16[0.11 ; 0.24] 11.2 \%$

$0.38[0.28 ; 0.48] 11.3 \%$

$0.18[0.12 ; 0.26] 11.2 \%$

$0.17[0.10 ; 0.27] 10.9 \%$

$0.13[0.06 ; 0.25] 10.4 \%$

$0.70[0.62 ; 0.78] 11.4 \%$

$0.27[0.15 ; 0.43] 100.0 \%$

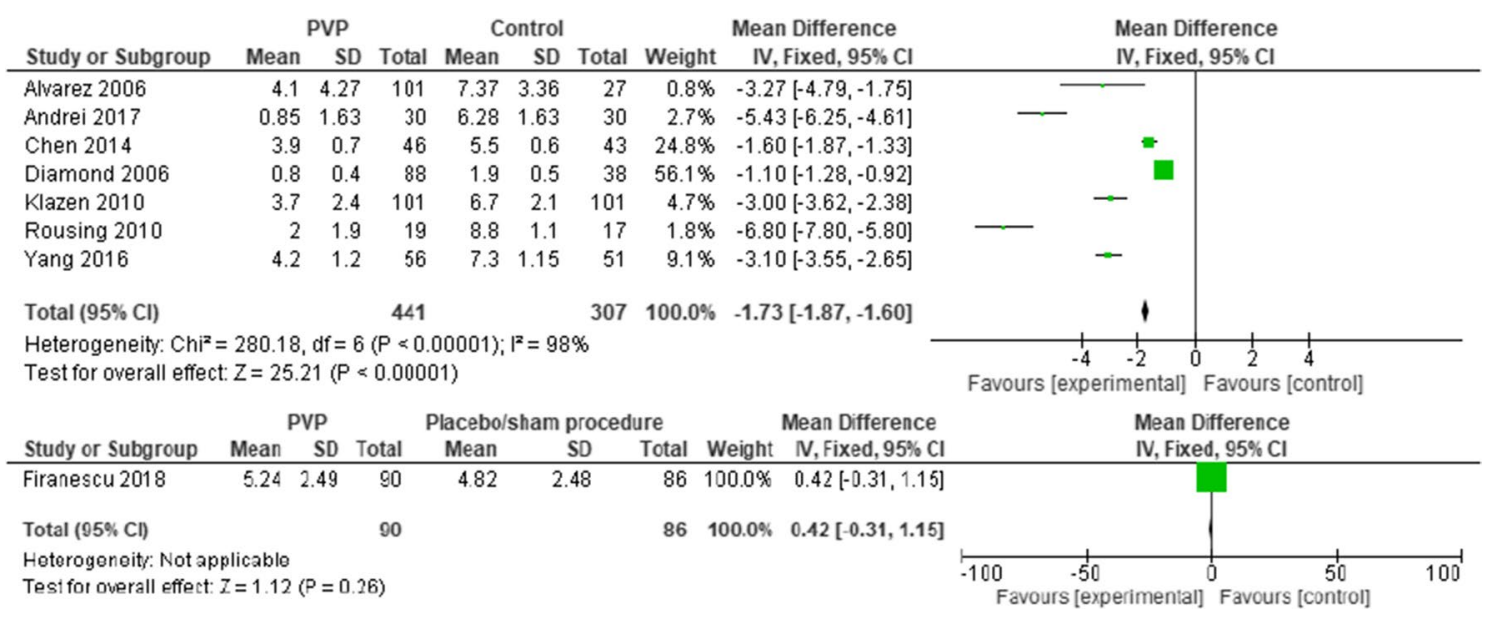

Fig. 3 Forest plot of patient-reported pain scores at day one postoperative

of eligible patients and high crossover rates in both studies have also been questioned. In the study of Kallmes et al., at 3-month follow-up, many patients in the control group (43\%) crossed over to the PV group due to persisting pain, as compared to the number of patients in the PV group who crossed over to the control group (12\%), a difference that reached statistical significance $(p<0.001)$. Finally, patients assigned to the sham procedures received injection of Bupivacaine into the periosteum next to the facet joints. However, in a study of Tischer et al., degenerative facet joint lesions were found on gross histologic analysis in $80 \%$ of the elderly, with most found at the L4-L5 level [35]. In the Framingham Heart Study, moderate or severe lumbar facet joint osteoarthritis on CT-imaging was present in $89 \%$ of those above 65 years of age [36]. Pain improvement rates after facet blocks or an medial branch block in patients with back pain has been reported in the range of $29-60 \%$ in the literature [37]. Park et al. reported a satisfaction level of "excellent" or "good" 12 months after the first injection in
$78.9 \%$ of the patients with osteoporotic spinal compression complaining of persistent low back pain [38]. In the series of Heui Seung Lee and the study of Kim et al., 69.6\% and 70\% of the patients have benefitted from a medial branch block for their back pain, respectively [39, 40]. In our systematic review, a tertiary analysis with a random effects model showed a substantial within-group reduction in VAS score of 3.6 (95\% CI: $\left.1.2 ; 3.0, p<0.001, I^{2}=93.0 \%\right)$ in a 6-month follow-up period for the sham groups. A blinded RCT studying the outcome of facet blocks against percutaneous cement augmentation in the elderly would be of great value.

Because of the results of the two sham trials of 2009, in some countries PV/PKP were not reimbursed anymore [41]. Ong et al. showed us that the mortality risk for VFC is high. In this study, more than two million patients were analyzed and the mortality in the overall VFC cohort was 85.1 (95\% CI 84.7-85.5) at 10 years. The conservativetreated group showed a $24 \%$ and $8 \%$ larger mortality risk than the PKP and $\mathrm{PV}$, respectively. The mortality 


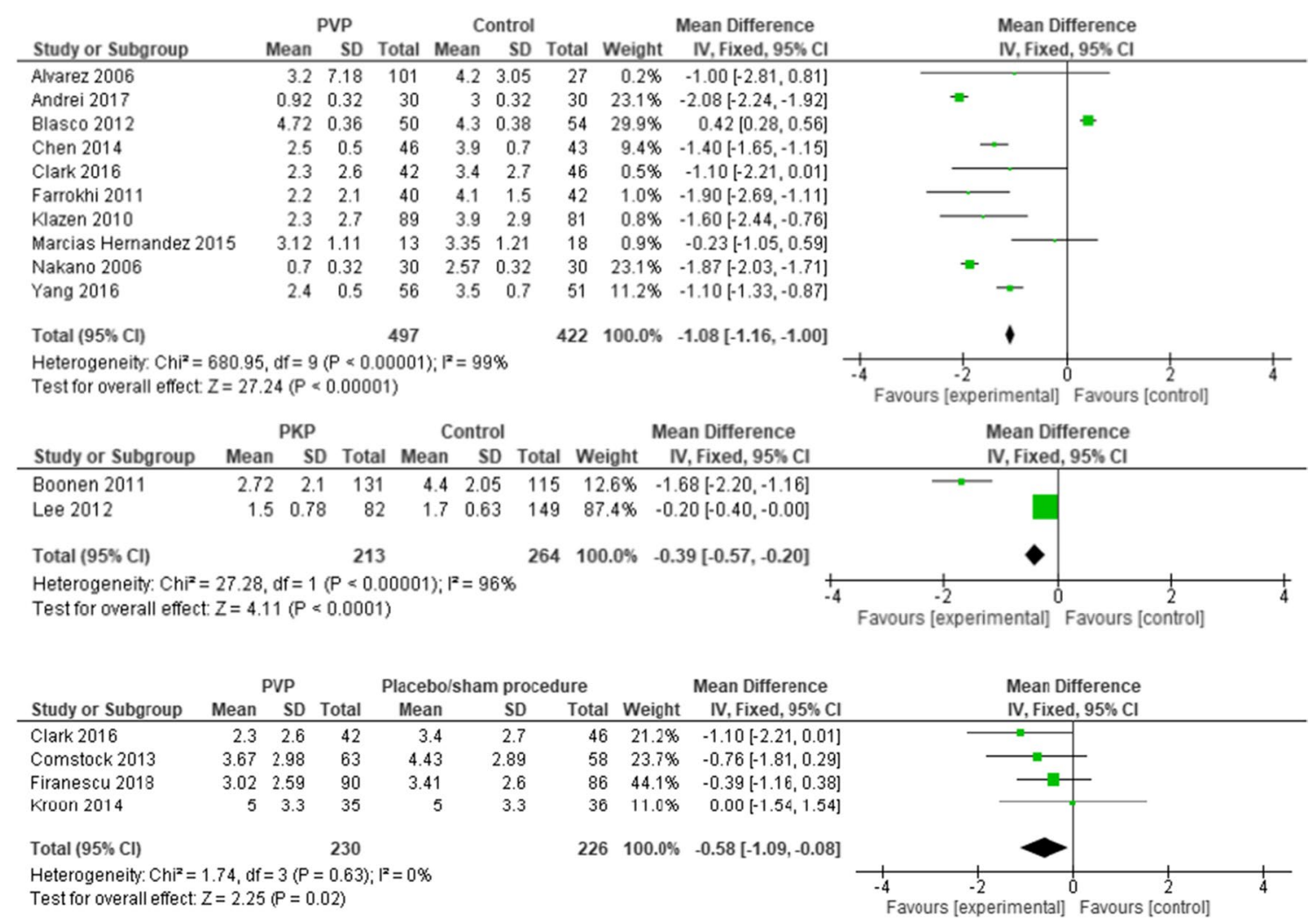

Fig. 4 Forest plots of pain at follow-up of 6 months

of patients was also significantly greater in the period 2010-2014 compared to 2005-2009 [42].

A more recently published blinded Australian trial comparing PV to placebo treating patients with a less than 6 weeks old fracture showed a larger mean reduction in pain in the PV group than in the placebo control group at all follow-up moments [12]. The patients in this trial were older, had higher pain scores and increased disability at enrollment than those patients in previous placebo-controlled trials. In contrast to previous trials in which the posterior vertebral cortex was anesthetized, this trial used local anesthesia subcutaneously. Also, this trial used odorless PMMA kits with a closed mixing and delivery system that was not opened during placebo procedures. Additionally, in this trial there was the absence of a crossover option and 57\% of patients were in-hospital patients, in contrast to the other placebo-controlled trials which excluded or did not report on these patients. A median reduction in 5.5 hospital days was achieved in the PV group of the VAPOUR trial. This trial has been criticized for its lack of generalizability and methodological flaws. On average, $84 \%$ of the patients were recruited from one institute, while the study was performed as a multicentre trial. Besides, comorbidities in the studied cohorts were not recorded and most subgroup analyses had a limited number of patients achieving outcome. The differences in results for primary outcomes of the placebocontrolled studies could be explained by inclusion criteria and study methodology.

The Cochrane vertebroplasty review of April 2018 was updated in November 2018 to address complaints to the Chief Editor of Cochrane about errors in the report [6]. There is ongoing debate that the review does not accurately report the evidence for vertebroplasty in patients with severe symptoms and early fractures.

The importance of early interventions positively affecting final outcome has already been studied in hip fractures, which have been traditionally regarded to represent frailty. A Canadian cohort of 42.230 patients with a mean age of 80 years found significant benefits of early surgery. Significantly lower 30-day mortality (5.8\% vs. 6.5\%), less postoperative complications and significantly less adverse outcomes at 30 days ( $10 \%$ vs. $12 \%)$ were found with early surgery $(<24 \mathrm{~h})$ [43]. Appropriate attention and early management are also needed for frail patients with OVFs because of reciprocal interaction. Frailty deficits worsen by fracture, and accelerated risk of OVFs arises by frailty [44]. Delaying surgical intervention in the fragile elderly can sometimes lead to suboptimal care. The results of recent RCTs suggest 


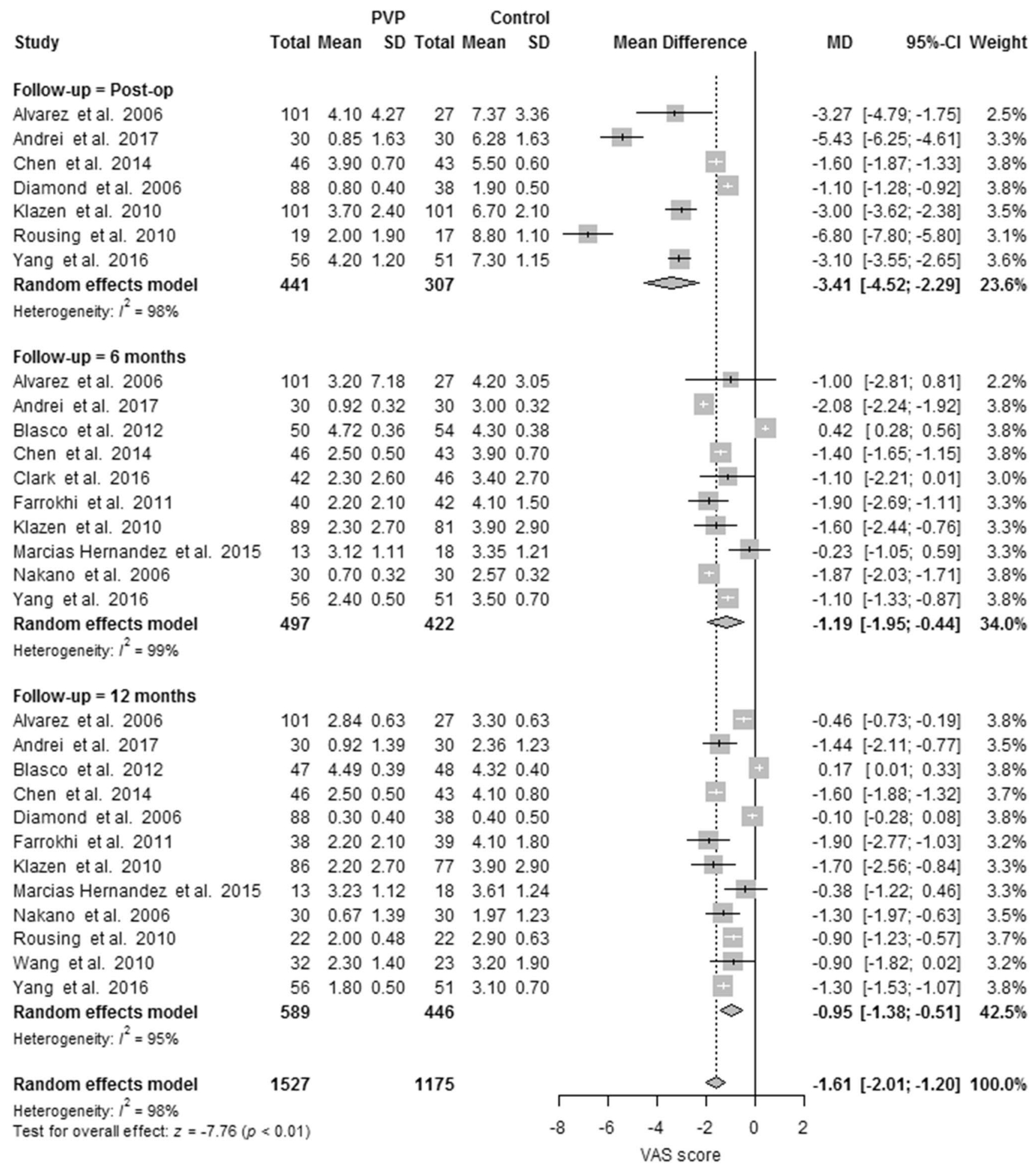

Fig. 5 Random effects model plot pains scores PVP versus conservative treatment up to 12 months

a shift to an earlier and more aggressive approach in the form of percutaneous cement augmentation instead of conservative treatment for acute and subacute thoracolumbar fractures in the elderly $[11,12]$.
Moreover, delayed diagnosis and lack of proactive management may result in a vicious circle with recurrent or prolonged hospitalization, acute and chronic back pain, polypharmacy with painkillers (often poorly tolerated by 




Fig. 6 Fixed effect model plot pain scores PVP versus sham treatment up to 12 months

the elderly population), reduced pulmonary function, failure in overall sagittal compensation and progressive spinal kyphosis with consequent loss of function and independency and potential premature death. Furthermore, severe osteoporosis and aging are risk factors for failure of conservative treatment $[23,45]$. In the study of Lee et al., a cutoff value of 76.5 years old was a risk factor for failure. The failure rate for early ( 3 weeks) conservative treatment was $35 \%$ in this study. Zhang et al. showed that a modified frailty index $(\mathrm{mFI})$ of $>3$ and severe osteoporosis were important risk factors for conservative treatment failure. The failure rate was $41 \%$ for early ( 3 weeks) conservative treatment.

In summary, many authors suggest to choose for conservative treatment in the early weeks after OVFs. Minimal invasive treatments like PV and PKP are indicated if conservative treatment fails. Elderly patients with osteoporotic fractures should be considered as frail elderly. In the frail elderly, prolonged non-effective conservative management can lead to a patient becoming bedridden with a range of complications and even premature death as a consequence. Besides, the increasing danger of opioid abuse should be recognized.

This systematic review is limited by the significant heterogeneity and moderate quality evidence of included studies. Potential bias cannot be excluded due to inadequate blinding of patients and personnel. In some studies, the control groups were formed by the population that rejected percutaneous cement augmentation, which introduces selection bias. Besides, conservative treatment characteristics varied considerably: offering bed rest, analgesia, a variation of rehabilitation program or brace treatment, and in one study, even intrathecal infusion was offered. In addition, outcome measures varied between studies. Adverse events of the procedures were not described in detail since most studies mainly focused on pain or function.

In this review, we conclude that in the frail elderly with (sub)acute OVF, severe pain despite early conservative measures, focal tenderness and edema on MRI scans concordant with the level of the fracture, when no absolute contraindications are present, percutaneous cement augmentation is safe and effective and can be offered to hasten return to normal function and bypass the consequences of prolonged immobilization. Given the limited methodological quality of included studies, the present findings should be confirmed with more high-quality and well-designed studies. 
RMDQ

\begin{tabular}{lll} 
Study or Subgroup Mean SD Total Mean SD Total Weight IV, Fixed, $95 \% \mathrm{Cl}$ & \\
\hline 5.3 .1 PVP vs Placebo/sham &
\end{tabular}

$\begin{array}{lrrrrrrrr}\text { Clark 2016 } & 11.7 & 6.5 & 49 & 7.4 & 6.9 & 51 & 1.6 \% & 4.30[1.67,6.93] \\ \text { Comstock 2013 } & 9.44 & 6.12 & 63 & 11.38 & 6.35 & 58 & 2.3 \% & -1.94[-4.17,0.29]\end{array}$

$\begin{array}{lrrrrrrrr}\text { Comstock 2013 } & 9.44 & 6.12 & 63 & 11.38 & 6.35 & 58 & 2.3 \% & -1.94[-4.17,0.29] \\ \text { Kroon 2014 } & 21.4 & 5.8 & 35 & 21 & 5.8 & 36 & 1.6 \% & 0.40[-2.30,3.10]\end{array}$

Subtotal $(95 \% \mathrm{CI})$

$147 \quad 218$

Heterogeneity: $\mathrm{Chi}^{2}=12.65, \mathrm{df}=2(\mathrm{P}=0.002) ; \mathrm{I}^{2}=84 \%$

Test for overall effect: $Z=0.81(P=0.42)$

5.3.2 PVP vs CT

$\begin{array}{lllllllll}\text { Chen } 2014 & 9.3 & 0.9 & 46 & 11.1 & 0.9 & 43 & 80.9 \% & -1.80[-2.17,-1.43]\end{array}$

$\begin{array}{lllllllll}\text { Klazen } 2010 & 9.27 & 3.6 & 89 & 10.77 & 4.2 & 81 & 8.1 \% & -1.50[-2.68,-0.32\end{array}$

$\begin{array}{lllll}\text { Subtotal }(95 \% \mathrm{Cl}) & 135 & 124 & 89.0 \% & -1.77[-2.13,-1.42]\end{array}$

Heterogeneity. $\mathrm{Chi}^{2}=0.23, \mathrm{df}=1(P=0.64) ; \mathrm{I}^{2}=0 \%$

Test for overall effect $Z=9.74(P<0.00001)$

5.3.3 PKP vs CT

Boonen 2011

Subtotal $(95 \%$

$8.44 \quad 5.4 \quad 131 \quad 11.33$

$6 \quad 115 \quad 5.5 \%-2.89[-4.32,-1.46]$

Heterogeneity. Not applicable

Test for overall effect: $Z=3.95(P \propto 0.0001)$

Total $(95 \% \mathrm{Cl})$

413

$115 \quad 5.5 \%-2.89[-4.32,-1.46]$

Heterogeneity. $\mathrm{Chi}^{2}=25.45, \mathrm{df}=5(\mathrm{P}=0.0001) ; \mathrm{I}^{2}=80 \%$

Test for overall effect: $Z=9.93(P<0.00001)$

Test for subaroup differences: $\mathrm{Chi}^{2}=12.57, \mathrm{df}=2(\mathrm{P}=0.002), \mathrm{I}^{2}=84.1 \%$

$384100.0 \% \quad-1.70[-2.04,-1.37]$

ODI

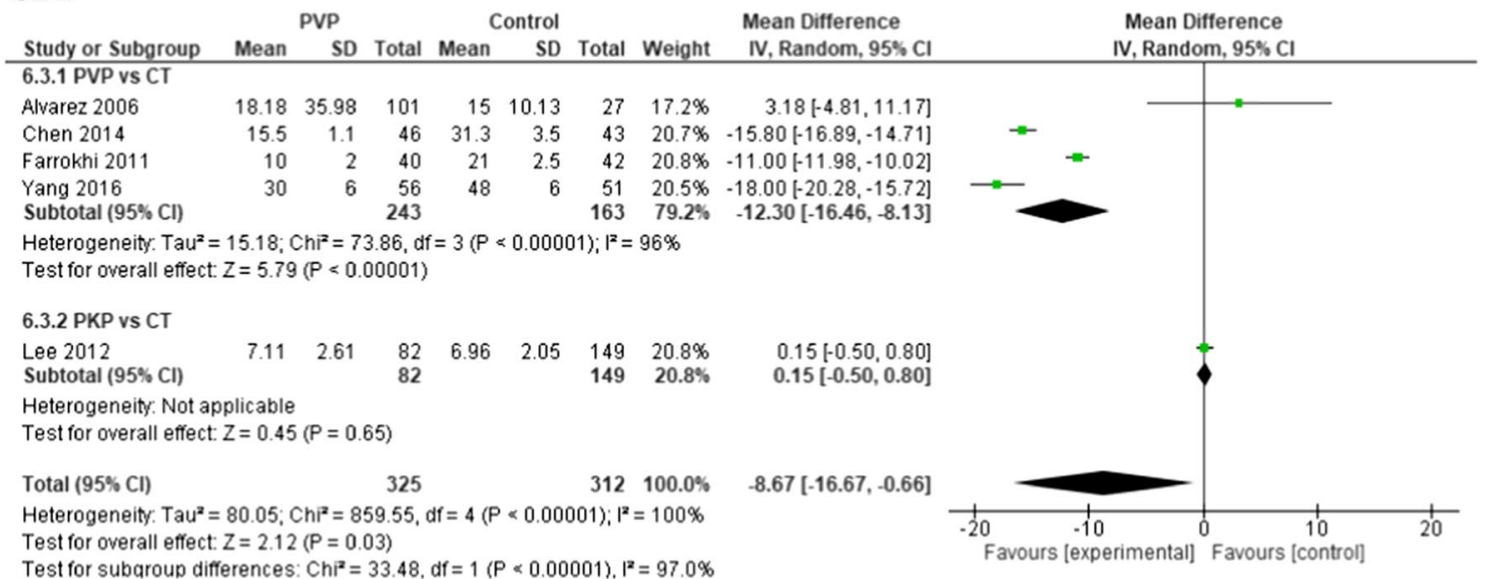

Fig. 7 Forest plots of functional outcome scores at follow-up of 6 months

QOL

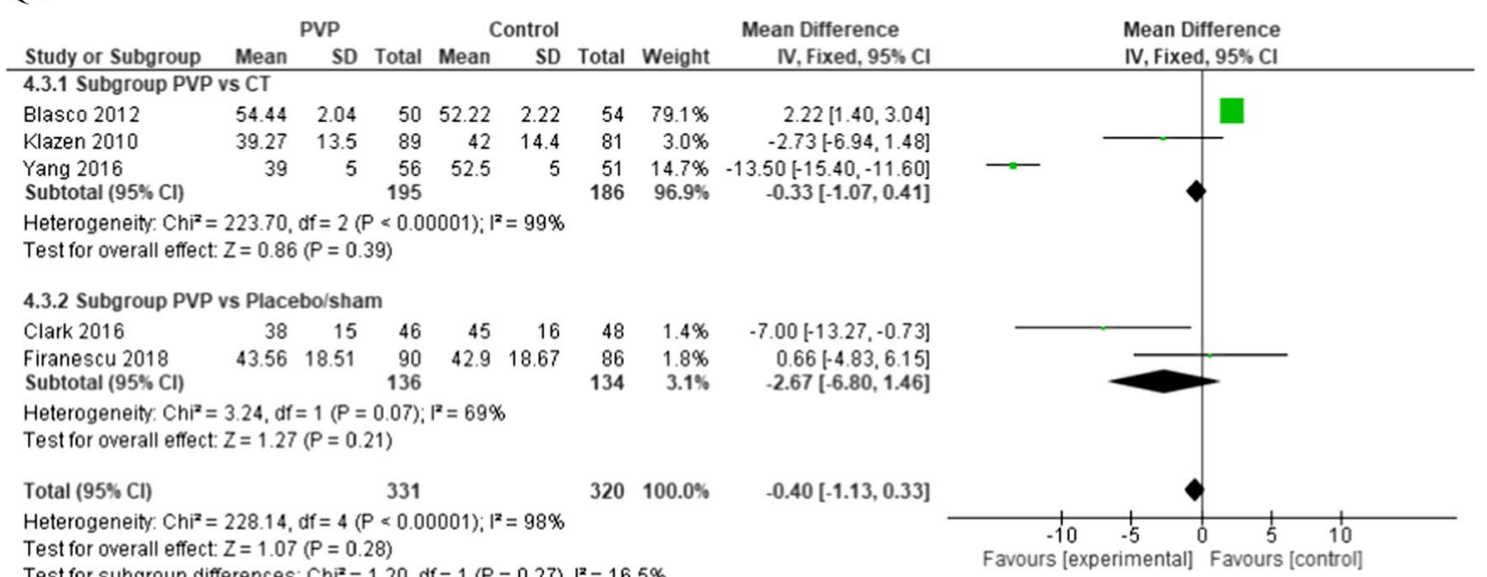

Fig. 8 Forest plots of QUALEFFO-41 outcome at follow-up of 6 months 
Acknowledgements We would like to thank Dr. J. Blasco, who provided additional data to complete this review.

Funding This research received no specific grant from any funding agency in the public, commercial or not-for-profit sectors. The corresponding author has full access to all the data in the study and bears full responsibility for submission.

\section{Compliance with ethical standards}

Conflict of interest The authors declare that they have no conflict of interest.

Open Access This article is licensed under a Creative Commons Attribution 4.0 International License, which permits use, sharing, adaptation, distribution and reproduction in any medium or format, as long as you give appropriate credit to the original author(s) and the source, provide a link to the Creative Commons licence, and indicate if changes were made. The images or other third party material in this article are included in the article's Creative Commons licence, unless indicated otherwise in a credit line to the material. If material is not included in the article's Creative Commons licence and your intended use is not permitted by statutory regulation or exceeds the permitted use, you will need to obtain permission directly from the copyright holder. To view a copy of this licence, visit http://creativecommons.org/licenses/by/4.0/.

\section{References}

1. Johnell O, Kanis JA (2006) An estimate of the worldwide prevalence and disability associated with osteoporotic fractures. Osteoporos Int 17:1726

2. Kanis JA (2002) Diagnosis of osteoporosis and assessment of fracture risk. Lancet 359:1929

3. Melton LJ III, Crowson CS, O'Fallon WM (1999) Fracture incidence in Olmsted County, Minnesota: comparison of urban with rural rates and changes in urban rates over time. Osteoporos Int 9:29

4. Cauley JA, Thompson DE, Ensrud KC et al (2000) Risk of mortality following clinical fractures. Osteoporos Int 11:556-561

5. Chen LX, Li YL, Ning GZ et al (2015) Comparative efficacy and tolerability of three treatments in old people with osteoporotic vertebral compression fracture: a network meta-analysis and systematic review. PLoS ONE 10(4):e0123153

6. Buchbinder R, Johnston RV, Rischin KJ et al (2018) Percutaneous vertebroplasty for osteoporotic vertebral compression fracture. Cochrane Database Syst Rev 4:CD006349

7. Higgins JPT, Altman DG, Sterne JAC (2008) Assessing-risk of bias in included studies. In: Cochrane handbook for systematic reviews of interventions version 5.1.0. The Cochrane Collaboration. http://www.cochrane-handbook.org/

8. Huskisson EC (1974) Measurement of pain. Lancet 2:1127-1131

9. Roland M, Fairbank J (2000) The Roland-Morris disability questionnaire and the oswestry disability questionnaire. Spine 25(24):3115-3124

10. Lips P, Cooper C, Agnusdei D et al (1999) Quality of life in patients with vertebral fractures: validation of the quality of life questionnaire of the European Foundation for Osteoporosis (QUALEFFO). Working party for quality of life of the European Foundation for osteoporosis. Osteoporos Int 10(2):150-160

11. Yang EZ, Xu JG, Huang GZ et al (2016) Percutaneous vertebroplasty versus conservative treatment in aged patients with acute osteoporotic vertebral compression fractures: a prospective randomized controlled clinical study. Spine 41(8):653-660
12. Clark W, Bird P, Gonski P et al (2016) Safety and efficacy of vertebroplasty for acute painful osteoporotic fractures (VAPOUR): a multicentre, randomised, double-blind, placebo-controlled trial. Lancet 388(10052):1408-1416

13. Kroon F, Staples M, Ebeling PR et al (2014) Two-year results of a randomized placebo-controlled trial of vertebroplasty for acute osteoporotic vertebral fractures. J Bone Miner Res 29(6):1346-1355

14. Chen Dong, An Zhi-Quan, Song Sa et al (2014) Percutaneous vertebroplasty compared with conservative treatment in patients with chronic painful osteoporotic spinal fractures. J Clin Neurosci 21(3):473-477

15. Comstock BA, Sitlani CM, Jarvik JG et al (2013) Investigational vertebroplasty safety and efficacy trial (INVEST): patient-reported outcomes through 1 year. Radiology 269(1):224-231

16. Blasco J, Martinez-Ferrer A, Macho J et al (2012) Effect of vertebroplasty on pain relief, quality of life, and the incidence of new vertebral fractures: a 12-month randomized follow-up, controlled trial. J Bone Miner Res 27(5):1159-1166

17. Boonen S, Van Meirhaeghe J, Bastian L et al (2011) Balloon kyphoplasty for the treatment of acute vertebral compression fractures: 2-year results from a randomized trial. J Bone Miner Res 26(7):1627-1637

18. Farrokhi MR, Alibai E, Maghami Z (2011) Randomized controlled trial of percutaneous vertebroplasty versus optimal medical management for the relief of pain and disability in acute osteoporotic vertebral compression fractures. J Neurosurg Spine 14(5):561-569

19. Klazen CA, Lohle PN, de Vries J et al (2010) Vertebroplasty versus conservative treatment in acute osteoporotic vertebral compression fractures (Vertos II): an open-label randomised trial. Lancet 376(9746):1085-1092

20. Rousing R, Hansen KL, Andersen MO et al (2010) Twelve-months follow-up in forty-nine patients with acute/semiacute osteoporotic vertebral fractures treated conservatively or with percutaneous vertebroplasty: a clinical randomized study. Spine 35(5):478-482

21. Andrei D, Popa I, Brad S et al (2017) The variability of vertebral body volume and pain associated with osteoporotic vertebral fractures: conservative treatment versus percutaneous transpedicular vertebroplasty. Int Orthop 41(5):963-968

22. Marcías-Hernández SI, Chávez-Arias DD, Miranda-Duarte A et al (2015) Percutaneous vertebroplasty versus conservative treatment and rehabilitation in women with vertebral fractures due to osteoporosis: a prospective comparative study. Rev Invest Clin 67(2):98-103

23. Lee HM, Park SY, Lee SH et al (2012) Comparative analysis of clinical outcomes in patients with osteoporotic vertebral compression fractures (OVCFs): conservative treatment versus balloon kyphoplasty. Spine J 12(11):998-1005

24. Wang HK, Lu K, Liang CL et al (2010) Comparing clinical outcomes following percutaneous vertebroplasty with conservative therapy for acute osteoporotic vertebral compression fractures. Pain Med 11(11):1659-1665

25. Nakano M, Hirano N, Ishihara $\mathrm{H}$ et al (2006) Calcium phosphate cement-based vertebroplasty compared with conservative treatment for osteoporotic compression fractures: a matched casecontrol study. J Neurosurg Spine 4(2):110-117

26. Alvarez L, Alcaraz M, Pérez-Higueras A et al (2006) Percutaneous vertebroplasty: functional improvement in patients with osteoporotic compression fractures. Spine 31(10):1113-1118

27. Diamond TH, Bryant C, Browne L et al (2006) Clinical outcomes after acute osteoporotic vertebral fractures: a 2-year nonrandomised trial comparing percutaneous vertebroplasty with conservative therapy. Med J Aust 184(3):113-117

28. Firanescu CE, de Vries J, Lodder P et al (2018) Vertebroplasty versus sham procedure for painful acute osteoporotic vertebral 
compression fractures (VERTOS IV): randomised sham controlled clinical trial. BMJ 361:k1551

29. Kanis JA, McCloskey EV, Johansson H et al (2013) European guidance for the diagnosis and management of osteoporosis in postmenopausal women. Osteoporos Int 24(1):23-57

30. Percutaneous vertebroplasty and percutaneous balloon kyphoplasty for the treatment of osteoporotic vertebral fractures. NICE Technology Appraisal Guidance [TA279] (2013)

31. American Academy of Orthopaedic Surgeons (2010) The treatment of symptomatic osteoporotic spinal compression fracturesguideline and evidence report. AAOS, Rosemont

32. Kallmes DF, Comstock BA, Heagerty PJ et al (2009) A randomized trial of vertebroplasty for osteoporotic spinal fractures. N Engl J Med 361(6):569-579

33. Buchbinder R, Osborne RH, Ebeling PR et al (2009) A randomized trial of vertebroplasty for painful osteoporotic vertebral fractures. N Engl J Med 361(6):557-568

34. Ks Ryu, Park CKJ (2009) The prognostic factors influencing on the therapeutic effect of percutaneous vertebroplasty in treating osteoporotic compression fractures. Korean Neurosurg Soc 45:16-23

35. Tischer T, Aktas T, Milz S, Putz RV (2005) Detailed pathological changes of human lumbar facet joints L1-L5 in elderly individuals. Eur Spine J 15:308-315

36. Suri P, Miyakoshi A, Hunter DJ et al (2011) Does lumbar spinal degeneration begin with the anterior structures? A study of the observed epidemiology in a community-based population. BMC Musculoskelet Disorders 12:202

37. Manchikanti L, Pampati V, Fellows B et al (2000) The diagnostic validity and therapeutic value of lumbar facet joint nerve blocks with or without adjuvant agents. Curr Rev Pain 4:337-344
38. Park KD, Jee H, Nam HS et al (2013) Effect of medial branch block in chronic facet joint pain for osteoporotic compression fracture: one year retrospective study. Ann Rehabil Med 37(2):191-201

39. Lee HS, Park SB, Lee SH et al (2015) The effect of medial branch block for low back pain in elderly patients. Nerve 1(1):15-19

40. Kim KT, Park SW, Kim YB et al (2006) The effect of lumbar medial branch block on low back pain. J Korean Neurosurg Soc 40:256-261

41. Hirsch JA, Chandra RV, Pampati V et al (2016) Analysis of vertebral augmentation practice patterns: a 2016 update. J Neurointerv Surg 8:1299-1304

42. Ong KL, Beall DP, Frohbergh M et al (2018) Were VCF patients at higher risk of mortality following the 2009 publication of the vertebroplasty "sham" trials? Osteoporos Int 29(2):375-383

43. Pincus D, Ravi B, Wasserstein D et al (2017) Association between wait time and 30-day mortality in adults undergoing hip fracture surgery. JAMA 318:1994

44. Kim Ho-Joong, Park Saejong, Park Soo-Hyun et al (2018) Prevalence of frailty in patients with osteoporotic vertebral compression fracture and its association with numbers of fractures. Yonsei Med J 59(2):317-324

45. Zhang JN, He X, Fan Y et al (2019) Risk factors for conservative treatment failure in acute vertebral compression fractures (OVCFs). Arch Osteoporosos 14:24

Publisher's Note Springer Nature remains neutral with regard to jurisdictional claims in published maps and institutional affiliations.

\section{Affiliations}

\section{Sanli · S. M. J. van Kuijk ${ }^{2}$ R. A. de Bie ${ }^{2}$ - L. W. van Rhijn ${ }^{1}$ P. C. Willems ${ }^{1}$}

I. Sanli

ilknursanli@hotmail.com

1 Department of Orthopaedic Surgery, Maastricht University Medical Centre+, P. Debyelaan 25, PO Box 5800, 6202 AZ Maastricht, The Netherlands
2 Department of Epidemiology, CAPHRI School for Public Health and Primary Care, Maastricht University, Maastricht, The Netherlands 